\title{
COMPORTAMENTOS DINÂMICOS EM UM REATOR INDUSTRIAL DE POLIMERIZAÇÃO EM FASE GASOSA
}

\author{
Nina Paula Gonçalves Salau* \\ ninaseenq.ufrgs.br \\ Jorge Otávio Trierweiler* \\ jorgeeenq.ufrgs.br
}

\author{
Argimiro Resende Secchi* \\ argedenq.ufrgs.br \\ Gustavo Alberto Neumann ${ }^{\dagger}$ \\ gustavo.neumannebraskem.com.br
}

\begin{abstract}
*Universidade Federal do Rio Grande do Sul, DEQ-UFRGS, Rua Sarmento Leite 288/24, CEP 90050-170 - Porto Alegre, RS - Brasil

${ }^{\dagger}$ Braskem S.A., III Pólo Petroquímico, Via Oeste Lote 5 - Passo Raso, CEP 95853-000 Triunfo, RS - Brasil
\end{abstract}

\begin{abstract}
(invited paper): In gas-phase ethylene polymerization reactors, tight temperature control is of utmost importance to ensure that the temperature in the reaction zone is kept above the dew point of reactants, yet below the melt point of the polymer. Another important point is that if the temperature was under open-loop conditions, these reactors are prone to instability and limit cycles, however can be easily stabilized with an appropriate temperature controller. In this work, a detailed study of the dynamic behavior of an industrial fluidized-bed polymerization reactor is carried out, with the location of bifurcation points and system stabilization by PID controller designed via optimization in the frequency domain.
\end{abstract}

KEYWORDS: Reatores de polimerização, comportamentos dinâmicos, estabilidade, controle de temperatura.

\section{RESUMO}

(artigo convidado): Nos reatores de polimerização em fase

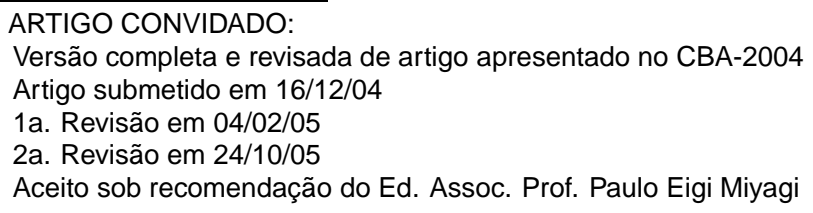

gasosa, o controle de temperatura em uma estreita faixa de temperatura é importantíssimo para assegurar que a temperatura na zona de reação seja mantida acima do ponto de orvalho dos reagentes, assim como abaixo do ponto de fusão do polímero. Outro ponto importante é que se a temperatura estiver em malha aberta, estes reatores estão propensos à instabilidade e ao surgimento de ciclos limites, entretanto podem ser facilmente estabilizados com um controlador de temperatura apropriado. Neste trabalho é realizado um estudo detalhado do comportamento dinâmico de um reator industrial de polimerização em leito fluidizado, com a localização de pontos de bifurcação e estabilização do sistema com controlador PID projetado via otimização no domínio da freqüência.

PALAVRAS-CHAVE: Polymerization reactors, dynamic behavior, stability, temperature control.

\section{INTRODUÇÃO}

A multiplicidade de estados estacionários e a instabilidade em reatores químicos são características de grande interesse industrial. Os primeiros autores a mostrarem a multiplicidade dos estados estacionários e o fenômeno da bifurcação em reatores de polimerização de etileno em leito fluidizado foram Choi e Ray (1985). Para tanto foi desenvolvido um modelo de reator levando em conta a transferência de massa e calor em leito fluidizado. 
Pinto (1991) apresenta resultados de cunho teórico e numérico e definições importantes no âmbito da Teoria Dinâmica de Sistemas Não-Lineares e da Teoria das Bifurcações. Apresenta também os principais resultados teóricos e experimentais obtidos para a confirmação da existência de comportamento oscilatório complexo em sistemas reais de interesse da Engenharia Química, em especial os reatores de polimerização.

Uma outra revisão sobre dinâmicas e estabilidade de reatores de polimerização pode ser encontrada em McAuley et al. (1995), contendo um breve histórico dos estudos do comportamento dinâmico em diversos tipos de reatores. Os autores também mostram que a adição de um sistema de recirculação de gás e de um sistema de troca térmica ao modelo de um reator em leito fluidizado possibilita o estudo detalhado do comportamento dinâmico e a localização de pontos de bifurcação. Além disso, podem ser vistos os efeitos da adição de um controlador da concentração de monômero ao sistema do reator, os efeitos das dinâmicas do trocador de calor e de seu tamanho e os efeitos das propriedades do catalisador e da composição do gás (monômero, co-monômero e inertes) na multiplicidade de soluções e dinâmica do reator.

Dadebo et al. (1997) demonstraram que sem um controlador feedback de temperatura, os reatores de polimerização em fase gasosa são suscetíveis a estados estacionários instáveis, ciclos limite e estados estacionários inaceitáveis de altas temperaturas. Neste trabalho, a habilidade dos controladores projetados para estabilizar os setpoints desejados é determinada usando aproximações por bifurcação.

Em Ray e Villa (2000) pode ser encontrada uma revisão sobre as dinâmicas não-lineares encontradas em uma grande variedade de processos de polimerização, nos quais são discutidos a multiplicidade dos estados estacionários, as oscilações e outros fenômenos não-lineares que surgem freqüentemente na prática industrial. O efeito do tamanho da partícula do polímero, da taxa de alimentação de catalisador e a da temperatura do gás de alimentação em um reator de polimerização de etileno em leito fluidizado (UNIPOLß) é analisado por Ghasem (1999).

Ghasem (2000) analisou o comportamento dinâmico de reatores de polimerização de etileno em leito fluidizado (UNIPOL) com o uso de um controlador PI, mostrando que, na maioria das vezes, é necessário operar o reator numa região de estados estacionários instáveis já que polímeros de boa qualidade são obtidos em temperaturas mais altas e que, por esta razão, é essencial estabilizar os ramos de estados estacionários instáveis.

Os estudos dos comportamentos dinâmicos não-lineares de reatores de polimerização em fase gasosa, encontrados na literatura, com detecção de multiplicidade de soluções e de instabilidade foram realizados através de aproximações nos parâmetros cinéticos do modelo destes reatores. No estudo feito neste trabalho, os comportamentos dinâmicos especiais, obtidos com o modelo do processo de polimerização

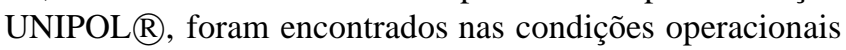
do reator industrial com a temperatura em malha aberta, sem o uso de qualquer aproximação nos seus parâmetros cinéticos.

Adicionalmente, demonstram-se os benefícios em operar um reator industrial com um controlador de temperatura adequado, a fim de estabilizar os estados estacionários instáveis encontrados em condições operacionais com a temperatura do reator em malha aberta.

\section{DESCRIÇÃO DO PROCESSO E MODE- LAGEM DO SISTEMA}

Na Figura 1, pode ser visto um esquema simplificado do processo. O reator é composto por uma zona de leito fluidizado e uma zona de seção expandida. Um trocador de calor é usado para remover o calor de reação do gás de reciclo. Após ser comprimido e resfriado, o gás de reciclo é misturado ao gás de alimentações e reinjetado na base do reator. $\mathrm{O}$ catalisador sólido é dosado e carregado por um fluxo de nitrogênio e injetado diretamente no leito. O produto é removido do leito fluidizado por um sistema de vasos de descarga que operam em ciclos determinados pela taxa de produção do reator. $\mathrm{Na}$ seção expandida, a composição do gás é analisada por cromatografia.

\subsection{Modelo do Processo UNIPOL}

O modelo do reator é composto por uma região ocupada por um leito fluidizado onde ocorre a reação (Kunni e Levenspiel, 1991, Choi e Ray, 1985) e uma seção expandida, que tem como objetivo misturar os gases provenientes do leito fluidizado e servir como reservatório de componentes gasosos.

A perda de calor através das paredes do reator não é considerada no equacionamento do modelo, pelo fato da mesma representar uma pequena parcela da remoção do calor gerado pela reação em um reator industrial. McAuley (1995) cita a possibilidade de mudança da dinâmica com a escala do reator (piloto para industrial), como estando associado às perdas de calor para parede.

Os gases incluídos na modelagem são os monômeros (eteno, buteno e hexeno), hidrogênio, nitrogênio, oxigênio e impurezas, todos considerados como gases ideais.

O sistema de recirculação de gás, existente nos reatores de leito fluidizado, é modelado através de balanços de energia 


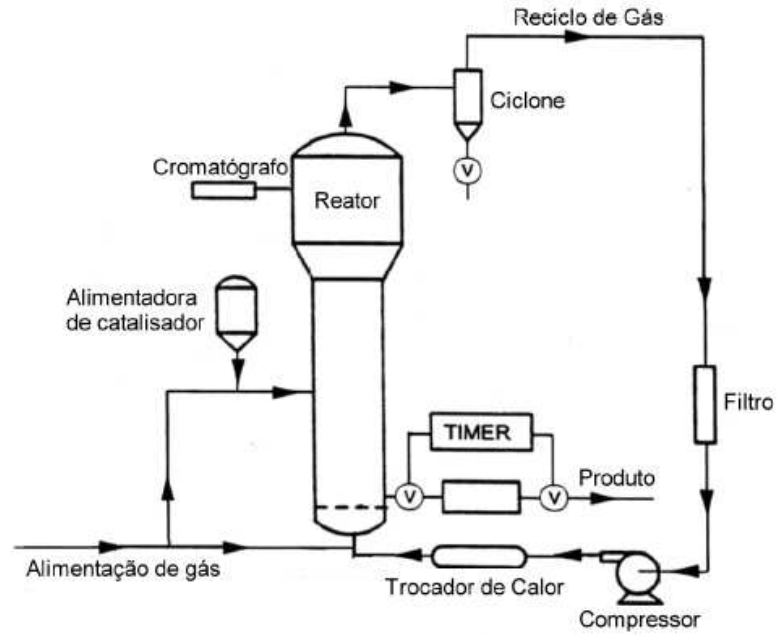

Figura 1: Esquema simplificado do processo (McAuley et al., 1994).

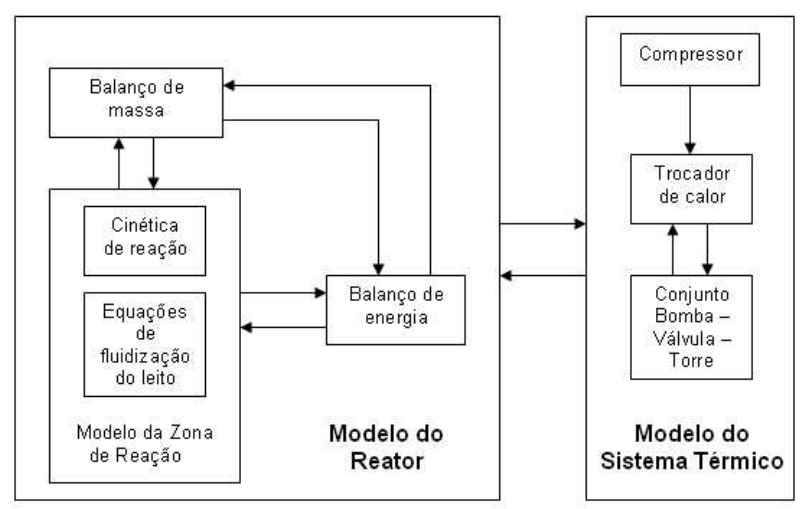

Figura 2: Esquema do modelo do processo UNIPOL $\mathbb{R}$

nos equipamentos existentes na linha. $\mathrm{Na}$ base do reator é feito um balanço de massa em um misturador da corrente de reciclo com a corrente de alimentação dos componentes gasosos.

O esquema do modelo do processo UNIPOL, descrito em detalhes nas próximas seções, pode ser visto na Figura 2.

\subsubsection{Modelo do Reator: Reações Cinéticas e Equações de Fluidização}

O modelo cinético foi desenvolvido por Gambetta (2001) para catalisadores de óxido de cromo. Este modelo cinético foi baseado no trabalho de Zacca (1995), McAuley (1991) e Xie et al. (1994), para catalisadores do tipo vanádio/titânio (Ziegler-Natta). Segundo McAuley et al. (1994) a cinética utilizada para catalisadores Ziegler-Natta pode ser estendida
Tabela 1: Reações usadas no modelo cinético

\begin{tabular}{|c|c|c|}
\hline $\begin{array}{l}\text { Ativação espontâ- } \\
\text { nea de sítios }\end{array}$ & $C_{P} \rightarrow P_{\overline{0}}^{k}$ & (1) \\
\hline $\begin{array}{l}\text { Ativação de sí- } \\
\text { tios pelo alquil- } \\
\text { alumínio }\end{array}$ & $C_{P}+A \rightarrow P_{\overline{0}}^{k}+B$ & (2) \\
\hline $\begin{array}{l}\text { Ativação de sítios } \\
\text { pelo hidrogênio }\end{array}$ & $C_{P}+H_{2} \rightarrow P_{\overline{0}}^{k}$ & (3) \\
\hline $\begin{array}{l}\text { Iniciação de cadeia } \\
\text { pelo monômero } i\end{array}$ & $P_{\overline{0}}^{k}+M_{i} \rightarrow P_{\bar{\delta}_{i}, i}^{k}$ & (4) \\
\hline $\begin{array}{l}\text { Propagação } \text { de } \\
\text { cadeia pelo monô- } \\
\text { mero j }\end{array}$ & $P_{\bar{n}, i}^{k}+M_{j} \rightarrow P_{\bar{n}+\bar{\delta}_{j}, j}^{k}$ & (5) \\
\hline $\begin{array}{l}\text { Transferência } \\
\text { espontânea de } \\
\text { cadeia }\end{array}$ & $P_{\bar{n}, i}^{k} \rightarrow P_{\overline{0}}^{k}+D_{\bar{n}}^{k}$ & (6) \\
\hline $\begin{array}{l}\text { Transferência } \\
\text { de cadeia pelo } \\
\text { monômero j }\end{array}$ & $P_{\bar{n}, i}^{k}+M_{j} \rightarrow D_{\bar{n}}^{k}+P_{\bar{\delta}_{j}, j}^{k}$ & (7) \\
\hline $\begin{array}{l}\text { Transferência } \\
\text { de cadeia pelo } \\
\text { hidrogênio }\end{array}$ & $P_{\bar{n}, i}^{k}+H_{2} \rightarrow P_{\overline{0}}^{k}+D_{\bar{n}}^{k}$ & (8) \\
\hline $\begin{array}{l}\text { Desativação espon- } \\
\text { tânea de sítios }\end{array}$ & $\begin{array}{l}P_{\bar{n}, i}^{k} \rightarrow C_{d}+D_{\bar{n}}^{k} \\
P_{\overline{0}}^{k} \rightarrow C_{d}\end{array}$ & (9) \\
\hline $\begin{array}{l}\text { Desativação de sí- } \\
\text { tios pelo hidrogênio }\end{array}$ & $\begin{array}{l}P_{\bar{n}, i}^{k}+H_{2} \rightarrow C_{d}+D_{\bar{n}}^{k} \\
P_{\overline{0}}^{k}+H_{2} \rightarrow C_{d}\end{array}$ & (10) \\
\hline $\begin{array}{l}\text { Desativação de sí- } \\
\text { tios pelo oxigênio }\end{array}$ & $\begin{array}{l}P_{\bar{n}, i}^{k}+O_{2} \rightarrow C_{d}+D_{\bar{n}}^{k} \\
P_{\overline{0}}^{k}+O_{2} \rightarrow C_{d}\end{array}$ & (11) \\
\hline $\begin{array}{lr}\text { Reação de eli- } \\
\text { minação } \\
\text { oxigênio de } \\
\text { alquil-alumínio }\end{array}$ & $A+O_{2} \rightarrow B$ & (12) \\
\hline
\end{tabular}

para catalisadores de cromo (Phillips). Na tabela 1 são mostradas as reações implementadas (onde) (considerando que) $C_{p}$ é o sítio potencial, $P_{\overline{0}}^{k}$ o sítio ativo do tipo $k, M_{i}$ o monômero do tipo $i, M_{j}$ o monômero do tipo $j, P_{\bar{\delta}, i}^{k}$ a cadeia de iniciação do monômero do tipo $i$ e o sítio do tipo $k, P_{\bar{n}, i}^{k}$ o polímero vivo com $\bar{n}$ monômeros, terminado no monômero do tipo $i$ e sítio $k, D_{\bar{n}}^{k}$ o polímero morto com $\bar{n}$ monômeros de sítio $k$, e $C_{d}$ é o sítio morto. $A, H_{2}, O_{2}$ e $B$ representam o alquil-alumínio, o hidrogênio, o oxigênio e o sub-produto, respectivamente.

Como pode ser visto nos itens anteriores, várias reações envolvem as cadeias de polímero em crescimento, as quais podem variar de uma unidade monomérica até infinito, de modo que, para manter o registro da quantidade de cada uma dessas espécies seriam necessários infinitos balanços de massa. Essa distribuição de comprimentos de cadeias poliméricas 
pode ser descrita pela definição dos momentos desta distribuição, possibilitando a modelagem de propriedades do polímero utilizando um número finito e razoável de equações diferenciais.

A distribuição de comprimentos de cadeias poliméricas, responsável por manter as informações das principais propriedades do polímero por tipo de sítio ou grupo de terminação, incluindo os pesos moleculares médios, polidispersão, número de cadeias de polímero vivo e morto, são descritos pelo mecanismo cinético acima e pelas definições dos momentos do polímero.

O conjunto básico das equações de fluidização do leito pode ser obtido em Choi e Ray (1985). Esse conjunto é utilizado em Lagemann (1989) e em Zacca (1995), sendo apresentado com algumas modificações em McAuley et al. (1994a). A referência principal utilizada em todos os trabalhos foi a primeira ou a segunda edição do livro de Kunii e Levenspiel (1991), onde a maioria dessas equações podem ser encontradas em sua forma original. A partir das equações de fluidização, foram obtidos a porosidade do leito e os volumes da fase gás, da seção expandida e da fase bolha, que são utilizados no balanço de massa dos principais gases do processo.

\subsection{Balanço Global de Massa}

Para obter as composições dos gases que estão incluídos no modelo, foi feito um balanço de massa para cada um destes componentes gasosos. De acordo com McAuley et al. (1994) é possível aproximar o leito (fase emulsão e fase bolha) por um reator CSTR. Também a conversão por ciclo no reator é muito baixa, dada pela baixa razão entre vazão mássica alimentada de monômero e vazão mássica do reciclo, chegando-se a conclusão que é possível considerar a composição dos gases da seção expandida similar a do leito. Os gases deixam o reator através da sua purga e da retirada do produto do reator, ou são consumidos pelas reações de polimerização, resultando nos balanços apresentados na Tabela 2

Tabela 2: Equações usadas no balanço de massa dos principais gases do processo

\begin{tabular}{|c|l|c|}
\hline Monômero $i$ & $\frac{d\left[M_{i}\right]}{d t}=\frac{\frac{W_{M_{i}}}{M_{M_{i}}}-\left(Q_{p} \cdot \varepsilon_{m f}+Q_{v}\right) \cdot\left[M_{i}\right]-R_{M_{i}}}{V_{g}+V_{d}+V_{b}}$ & (13) \\
\hline Hidrogênio & $\frac{d\left[H_{2}\right]}{d t}=\frac{\frac{W_{H_{2}}}{M_{H_{2}}}-\left(Q_{p} \cdot \varepsilon_{m f}+Q_{v}\right) \cdot\left[H_{2}\right]-R_{H_{2}}}{V_{g}+V_{d}+V_{b}}$ & $(14)$ \\
\hline Nitrogênio & $\frac{d\left[N_{2}\right]}{d t}=\frac{\frac{W_{N_{2}}}{M_{N_{2}}}-\left(Q_{p} \cdot \varepsilon_{m f}+Q_{v}\right) \cdot\left[N_{2}\right]}{V_{g}+V_{d}+V_{b}}$ & $(15)$ \\
\hline Oxigênio & $\frac{d\left[O_{2}\right]}{d t}=\frac{\frac{W_{O_{2}}}{M_{O_{2}}}-\left(Q_{p} \cdot \varepsilon_{m f}+Q_{v}\right) \cdot\left[O_{2}\right]-R_{O_{2}}}{V_{g}+V_{d}+V_{b}}$ & (16) \\
\hline
\end{tabular}

onde $\left[M_{i}\right],\left[H_{2}\right],\left[N_{2}\right]$ e $\left[\mathrm{O}_{2}\right]$ são, respectivamente, as con- centração molares de monômero $i$, hidrogênio, nitrogênio e oxigênio no reator, $W_{M i}, W_{H 2}, W_{N 2}$ e $W_{O 2}$ são, respectivamente, as vazões mássicas de monômero $i$, hidrogênio, nitrogênio e oxigênio, $\bar{M}_{M_{i}}, \bar{M}_{H_{2}}, \bar{M}_{N_{2}}$ e $\bar{M}_{O_{2}}$ são suas massas molares, $Q_{p}$ é a vazão volumétrica da retirada de produto, $\varepsilon_{m f}$ é a porosidade do leito, $Q_{v}$ é a vazão volumétrica da purga, $R_{M i}$ e $R_{O 2}$ são as taxas de reação do monômero $i$ e do oxigênio. $V_{g}, V_{d}$ e $V_{b}$ são os volumes da fase gás, da seção expandida e da fase bolha, respectivamente.

\subsection{Balanço Global de Energia}

Para desenvolver o balanço de energia para o reator, considerou-se a temperatura do reator como sendo uniforme (McAuley et al., 1995; Dadebo et al. 1997). A perda de calor através das paredes do reator não é considerada no equacionamento do modelo pelo fato da mesma representar uma pequena parcela da remoção do calor gerado pela reação. $\mathrm{O}$ balanço de energia do reator é dado por:

$$
\frac{d T}{d t}=\frac{H_{f}+H_{g}-H_{t o p}+H_{R}}{m_{s} \cdot c_{p s}}
$$

Os termos da Equação 17 e suas respectivas equações estão deduzidos na Tabela 3.

Tabela 3: Equações usadas no balanço de energia do processo

\begin{tabular}{|l|l|c|}
\hline $\begin{array}{l}\text { Capacidade } \\
\text { térmica do reator }\end{array}$ & $m_{s} \cdot c_{p_{s}}=m_{R} \cdot c_{p_{R}}+m_{B} \cdot c_{p_{B}}$ & $(18)$ \\
\hline $\begin{array}{l}\text { Entalpia associ- } \\
\text { ada às alimenta- } \\
\text { ções frescas do } \\
\text { reator }\end{array}$ & $H_{f}=W_{f} \cdot c_{p_{f}} \cdot\left(T_{f}-T_{r e f}\right)$ & $(19)$ \\
\hline $\begin{array}{l}\text { Entalpia asso- } \\
\text { ciada ao gás de } \\
\text { reciclo que entra } \\
\text { no reator }\end{array}$ & $H_{g}=W_{r} \cdot c_{p_{0}} \cdot\left(T_{0}-T_{r e f}\right)$ & $(20)$ \\
\hline $\begin{array}{l}\text { Entalpia associ- } \\
\text { ada ao polímero e } \\
\text { ao gás de reciclo } \\
\text { que deixam o } \\
\text { reator }\end{array}$ & \begin{tabular}{l}
$H_{t o p}=W_{p} \cdot c_{p_{p o l}} \cdot\left(T-T_{r e f}\right)+$ \\
\hline $\begin{array}{l}\text { Entalpia associ- } \\
\text { ada à reação que } \\
\text { ocorre no reator }\end{array}$
\end{tabular} & $\begin{array}{l} \\
\left(W_{p_{g}} \cdot\left(T-T_{r e f}\right)\right.\end{array}$ \\
\hline
\end{tabular}

$m_{R}$ é a massa metálica (aço-carbono) do reator e $c_{p_{R}}$, seu calor específico. $m_{B}$ é a massa do leito e $c_{p_{B}}$, seu calor específico. $T_{r e f}$ é a temperatura de referência do sistema. $W_{f}, c_{p_{f}}$ e $T_{f}$ são a vazão mássica total, o calor específico e a temperatura ponderada das alimentações, respectivamente. $W_{r}$ é a vazão mássica do gás de reciclo, onde $c_{p_{g}}$ e $c_{p_{0}}$ são os seus calores específicos na temperatura do reator, $T$, e 
na sua temperatura na base do reator, $T_{0}$, respectivamente. $W_{p}$ e $c_{p_{p o l}}$ são, respectivamente, a vazão mássica do produto retirado e o calor específico do polímero. mon $_{\text {inc }}$ representa o monômero incorporado e $\left(-\Delta H_{R}\right)$ o calor da reação.

\subsection{Modelo do Sistema de Troca Térmica}

A modelagem do sistema térmico do reator UNIPOLßtem como objetivo predizer a temperatura do gás de reciclo do reator na realimentação do reator. A predição desta variável é muito importante no estudo do controle da temperatura do leito do reator. Uma vez que todo o calor gerado pela reação é transferido para o gás de reciclo para que posteriormente seja removido durante o resfriamento no trocador de calor, conhecer seu valor permite uma boa estimativa da eficiência da troca térmica. Na Figura 3 podem ser vistos os equipamentos e os medidores de temperatura e vazão existentes no circuito térmico do sistema UNIPOLß)abordado neste trabalho.

Conforme pode ser visto na Figura 3, a ligação entre o reator e o trocador é feita através do circuito de recirculação de gás, sendo que no caminho entre estes dois equipamentos há um compressor.

Sabendo que, devido à velocidade e à quantidade de gás no reciclo, apesar da distância entre os equipamentos, pode-se considerar que:

a) o gás de reciclo na entrada do compressor está na mesma temperatura do gás na saída do reator;

b) o gás de reciclo na saída do compressor está na mesma temperatura do gás de reciclo na entrada do trocador de calor;

c) o gás de reciclo na saída do trocador de calor está na mesma temperatura do gás na entrada do reator.

Com estas considerações, um balanço de energia pode ser feito no compressor para obter a temperatura do gás de reciclo na entrada do trocador de calor e, com isso, substituir uma variável medida na planta (medidor $\mathrm{n}^{o} 1$ - indicador de temperatura no circuito térmico da Figura 3) por uma predição do modelo e fazer a conexão entre o modelo do reator e o modelo de sistema térmico.

Através de um balanço de massa e energia em torno do conjunto formado pela bomba de reciclo de água, válvula de água para resfriamento e torre de resfriamento, é possível determinar a temperatura em que a água resfriada entra no trocador de calor (medidor $n^{o} 6$ - indicador de temperatura no circuito térmico da Figura 3).

Com o intuito de estabelecer um modelo para a relação entre

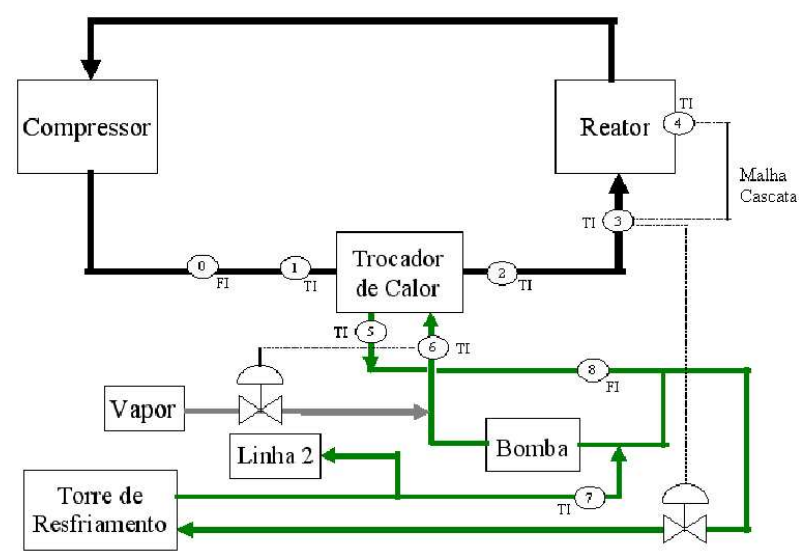

Figura 3: Esquema do sistema de troca térmica do processo

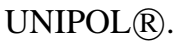

a abertura da válvula e a vazão de água para a torre de resfriamento, escolheu-se como função matemática representativa para desta relação, a função sigmóide $f(x)$ :

$$
f(x)=\frac{a}{1+c \cdot e^{-b . x}}
$$

Por regressão, obteve-se os parâmetros $a, b$ e $c$ dessa função para o conjunto de dados industriais utilizado. Assim, a variação adimensional da vazão de água para a torre de resfriamento em função da abertura da válvula pode ser representada por:

$$
W_{t w}(T C V)=\frac{1}{1+200 \cdot e^{-0,09 . T C V}}
$$

onde $W_{t w}$ é a vazão mássica da água a ser resfriada na torre de resfriamento e $T C V$ é a abertura da válvula de água para a torre de resfriamento. $\mathrm{O}$ parâmetro $a$ tem valor unitário, pois está sendo mostrada a vazão normalizada, mas esse parâmetro está relacionado com a máxima vazão de água na válvula (abertura de 100\%). A Figura 4 mostra que a Equação 24 representa bem os dados industriais na faixa de 25 a $100 \%$ de abertura da válvula.

O trocador de calor deste sistema, mostrado na Figura 3, é do tipo casco e tubos com fluxo em contra-corrente e passe simples. A troca térmica ocorre entre o gás de reciclo que passa pelo lado dos tubos e a água proveniente da torre de resfriamento que passa pelo lado dos cascos deste trocador. A modelagem deste equipamento está descrita mais detalhadamente na próxima seção.

\subsubsection{Modelo do Trocador de Calor}

Em Dadebo et al. (1997) foram desenvolvidos três diferentes modelos de trocadores de calor com complexidade variável, 


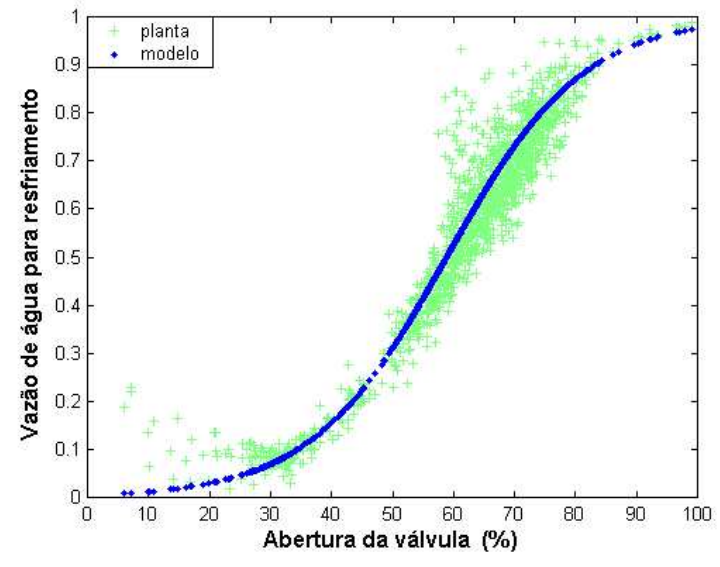

Figura 4: Comparação entre os dados da planta e o modelo obtido para a relação entre a abertura da válvula e a vazão de água para a torre de resfriamento.

usados para simulação do sistema de remoção de calor e para o projeto e teste dos controladores de temperatura.

Os três modelos desenvolvidos por Dadebo et al. (1997) foram implementados no processo UNIPOL $($, apresentado neste trabalho. Através de simulações com dados da planta industrial, foi feita a avaliação de qual destes modelos reproduz melhor o comportamento deste sistema.

Um destes modelos de troca térmica é muito simples, obtido através da imposição de dinâmicas de primeira ordem na taxa de remoção de calor com uma constante de tempo correspondente, $\tau$, para reproduzir um modelo dinâmico linear. Esta aproximação de primeira ordem reproduz apenas uma taxa de remoção de calor aproximada do sistema, por isso os resultados obtidos na comparação com dados industriais, embora satisfatórios, não serão considerados.

Uma representação mais precisa do sistema de remoção de calor pode ser obtida usando um modelo de trocador de calor com estágios de troca térmica. Os modelos de trocador de calor com estágios podem fornecer predições razoáveis do perfil da temperatura sobre uma determinada faixa de condições operacionais. Uma discussão sobre a precisão da modelagem dinâmica no processo de troca térmica é vista em Alsop e Edgar (1989), onde os autores propõem que o trocador de calor seja modelado como uma série de pequenos trocadores em série cujo fluxo está em contra-corrente, considerando mistura perfeita do fluido para cada uma das pequenas subseções do trocador. O modelo usa poucos estágios para manter um número mínimo de estados de temperatura, através da redução da complexidade do sistema, ainda que usando estágios suficientes para suportar que a temperatura do fluido fosse considerada uniforme em cada seção do trocador.

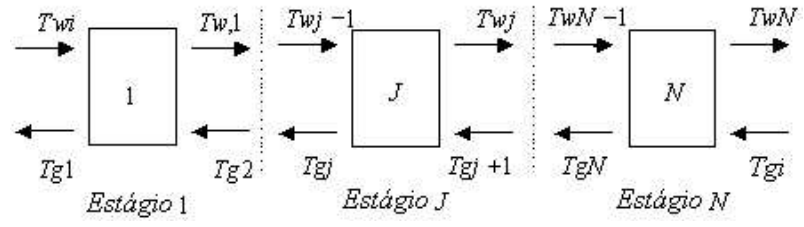

Figura 5: Esquema do modelo do trocador de calor com $\mathrm{N}$ estágios de troca térmica.

Um trocador com $\mathrm{N}$ estágios de troca térmica está ilustrado, com os eixos apropriados de temperatura, na Figura 5. O trocador de passe simples foi dividido em um número de estágios com área de troca térmica equivalente.

Dois tipos de modelos são considerados: o modelo convencional de força motriz com média logarítmica da variação da temperatura (LMTD) e um modelo de força motriz com variação linear da temperatura (LTD) (Dadebo et al., 1997). A variação linear da temperatura do modelo LTD mostrou-se adequada ao considerar apenas um estágio de troca térmica. Para 2 ou mais estágios, essa equação mostrou-se equivocada, necessitando de uma adaptação. Para isso, usou-se a média aritmética de temperatura (AMTD) para o caso do trocador do processo UNIPOL $\AA$. Assim, os modelos considerados são os seguintes:

O modelo genérico de troca térmica está escrito nas equações a seguir:

$$
\begin{aligned}
\frac{d T_{w, j}}{d t} & =\frac{N \cdot F_{w}}{M_{I w}}\left(T_{w, j-1}-T_{w, j}\right)-\frac{U \cdot A_{t}}{M_{I w} \cdot \bar{c}_{p w}} \Delta T \\
\frac{d T_{g, j}}{d t} & =\frac{N \cdot F_{0}}{M_{I 0}}\left(T_{g, j+1}-T_{g, j}\right)+\frac{U A_{t}}{M_{I 0} \cdot \bar{c}_{p 0}} \Delta T
\end{aligned}
$$

Onde $j=1, \ldots, N$ e $\Delta T$ é a diferença de temperatura média entre a água e o gás no estágio $j$, conforme o modelo usado (LMDT, LTD ou AMTD). $M_{I w}$ e $M_{I 0}$ são os inventários totais molares nos lados da água e do gás no trocador de calor, respectivamente. $F_{w}$ e $F_{0}$ são as vazões de água de resfriamento e de gás de reciclo, respectivamente. $\bar{c}_{p w}$ e $\bar{c}_{p 0}$ são, respectivamente, o calor específico isobárico da água e do gás de reciclo. $T_{g, N+1}\left(=T_{g i}\right)$ é a temperatura do gás e $T_{w, 0}\left(=T_{w i}\right)$ é a temperatura da água que estão entrando no trocador de calor. $T_{g, j}$ e $T_{w, j}$ representam a temperatura do gás e da água, respectivamente, deixando o estágio $j$ do trocador de calor. Na Tabela 4, pode ser visto o valor do termo $\Delta T$ para cada um dos modelos.

Comparação entre os modelos com estágios de troca térmica Foi feita uma comparação entre os modelos LMTD e LTD+ AMTD, no qual o número de estágios de troca térmica do modelo LTD+AMTD foi variado para determinar quantos 
Tabela 4: Valor do termo $\Delta T$ nos modelos térmicos estudados

\begin{tabular}{|l|c|}
\hline $\begin{array}{l}\text { Modelo } \\
\text { Térmico }\end{array}$ & Termo $\Delta T$ \\
\hline LMTD & $\Delta T_{l m, j}=\frac{\left(T_{w, j}-T_{g, j+1}\right)-\left(T_{w, j-1}-T_{g, j}\right)}{\ln \frac{\left(T_{w, j}-T_{g, j+1}\right)}{\left(T_{w, j-1}-T_{g, j}\right)}}$ \\
\hline LTD & $\Delta T_{j}=\left(T_{w, j}-T_{g, j}\right)$ \\
\hline AMTD & $\Delta T_{a m, j}=\frac{1}{2} \cdot\left[\left(T_{w, j}-T_{g, j+1}\right)+\left(T_{w, j-1}-T_{g, j}\right)\right]$ \\
\hline
\end{tabular}

estágios de troca térmica são necessários neste modelo para que este apresente a mesma resposta do modelo LMTD, em comparação aos dados da planta industrial.

A partir da análise dos gráficos da Figura 6, verifica-se que é necessário no mínimo 4 estágios de troca térmica no modelo LTD+AMTD, para que se obtenha um comportamento semelhante ao modelo LMTD com apenas um estágio e que um número maior de estágios, como no caso de dez estágios, não causa melhoria significante na resposta deste modelo térmico.

Além disso, outra vantagem desse modelo é a redução do sistema, pois em um modelo com um estágio de troca térmica são necessárias apenas 2 equações diferenciais ordinárias (EDO's) e num modelo com 4 estágios, necessita-se de 8 EDO's. Um número menor de EDO's proporciona uma simulação mais rápida.

Em seu trabalho, Dadebo et al. (1997) fizeram um estudo para determinar a variação das temperaturas de entrada e saída do gás de reciclo e da água de resfriamento nos estágios de troca térmica ao longo do comprimento do trocador de calor. Este estudo, reproduzido aqui, tem por objetivo explicar a diferença do comportamento dos modelos LMTD e LTD+AMTD em relação à variação no número de estágios de troca térmica no trocador de calor.

O trocador de calor do sistema UNIPOL $®$, conforme já descrito, trata-se de um trocador com passe simples e fluxo em contracorrente. $\mathrm{O}$ eixo das abscissas da Figura 7 representa o comprimento do trocador de calor, onde o gás de reciclo entra pelo lado direito e deixa o trocador pelo lado esquerdo. $\mathrm{O}$ contrário acontece com a água de resfriamento, que entra pelo lado esquerdo e deixa o trocador de calor pelo lado direito.

Pelos resultados mostrados na Figura 7, observa-se que no modelo térmico LMTD, o gás de reciclo e a água de resfriamento entram, respectivamente, no último e no primeiro estágio de troca térmica a mesma temperatura, para qualquer número de estágios. No modelo térmico LTD+AMTD, o gás de reciclo entra a mesma temperatura no último estágio (para qualquer número de estágios), mas a água de resfriamento não entra a mesma temperatura no primeiro estágio de troca térmica para um número total de estágios de um e dois, o que demonstra que a temperatura da água de resfriamento é depende do número de estágios.

A temperatura da água de resfriamento depende da precisão do modelo do balanço de energia do trocador de calor, pois a entrada da água depende da saída do modelo, que vai depois compor o balanço de energia no misturador do reciclo de água que sai do trocador de calor e da água que vem da torre de resfriamento. Nesse caso, um estágio de troca térmica não é suficiente para prescrever corretamente o efeito contra-corrente para o modelo LTD+AMTD, precisando no mínimo de 4 estágios. Essa conclusão reforça os resultados do estudo demonstrado na Figura 6.

\section{COMPARAÇÃO DO MODELO DO PRO- CESSO COM DADOS DA PLANTA IN- DUSTRIAL}

O modelo desenvolvido foi implementado no software MATLAB $($ para o ajuste de seus parâmetros com dados da planta industrial, simulações dinâmicas e análise do controlador de temperatura. A comparação de um conjunto de dados de validação da planta industrial com o modelo pode ser observada na Figura 8, onde foi simulado um período de 40 horas de operação do reator.

Observa-se que o modelo descreve adequadamente o comportamento dinâmico da planta, apresentando um desvio estacionário de no máximo $8 \%$ na produção do reator, valor aceitável no estudo dos comportamentos dinâmicos e do controle de temperatura do reator, propostos neste trabalho, pois as perdas de reagentes que ocorrem na planta não foram contabilizadas no modelo. Estas perdas fazem com que na planta real a vazão de eteno da alimentação seja maior do que a prevista pelo modelo, gerando uma maior produção.

\section{ANÁLISE DE ESTABILIDADE}

Sistemas dinâmicos podem ser comumente representados por equações diferencias definidas em um espaço de estado finito ou infinito. Considerando o caso de dimensão finita, representado por um conjunto de $n$ equações diferenciais ordinárias (EDOs):

$$
\dot{y}=f(y, \lambda), \quad y \in R^{n}
$$

onde $y$ é o vetor das variáveis dependentes ou estados do sistema e $\lambda$ representa um ou mais parâmetros livres em cujo espaço paramétrico deseja-se analisar o comportamento dinâmico do sistema.

O modelo completo do sistema abordado neste artigo, formado por um conjunto de $60 \mathrm{EDOs}$, foi usado na análise da 


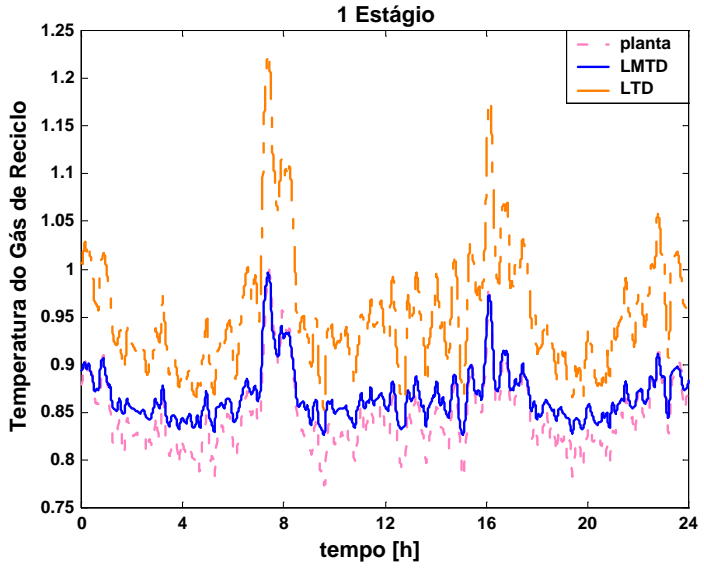

(a)

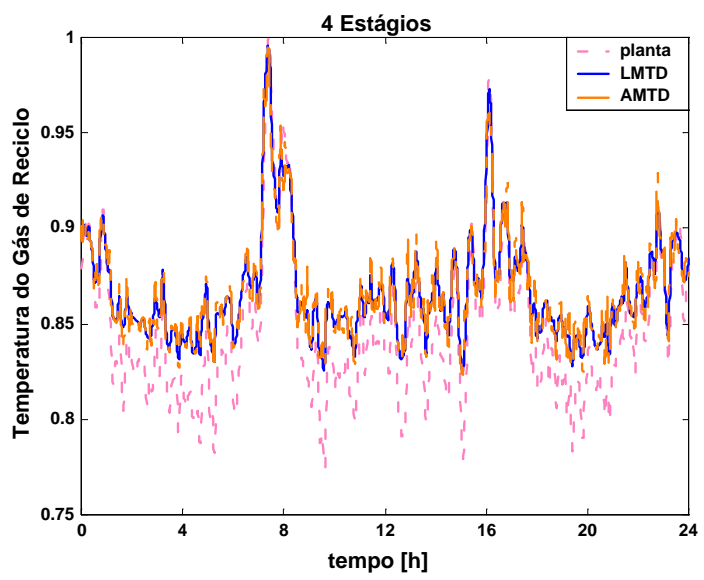

(c)

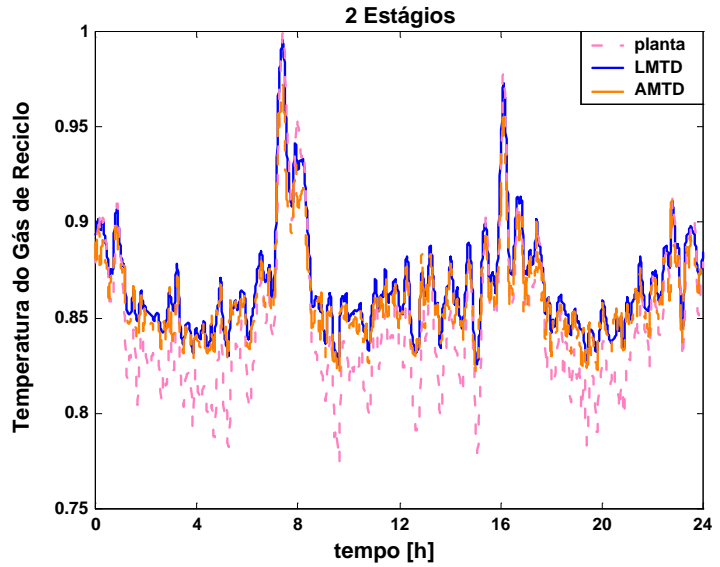

(b)

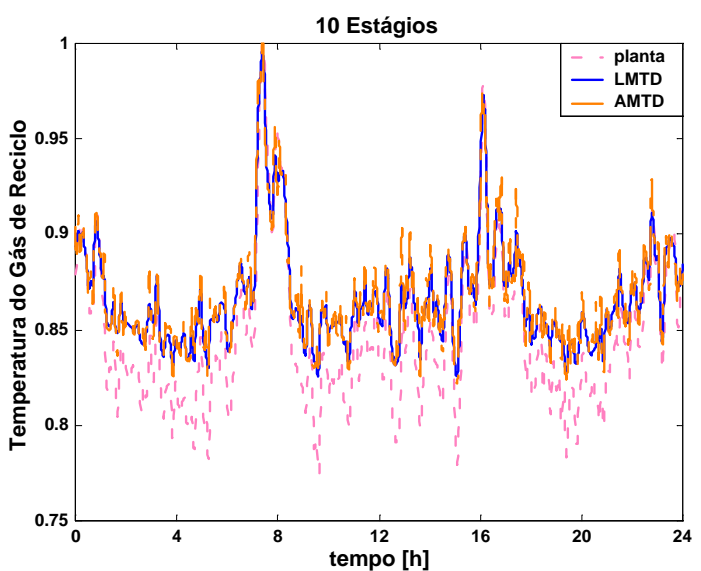

(d)

Figura 6: Comparação entre os dados industriais da temperatura do gás de reciclo nos modelos com força motriz LTD+AMTD e no modelo com força motriz LMTD para número de estágios variados: um (a), dois (b), quatro (c) e dez (d).

estabilidade do reator industrial supondo que a sua temperatura esteja em malha aberta, por se tratar da variável de interesse para o projeto do controlador. Utilizando as condições operacionais reais da planta industrial na simulação do modelo dinâmico do sistema, ocorreu o surgimento de estados estacionários instáveis e a formação de ciclos limites estáveis, a partir da implementação de um controlador da pressão total do reator, cuja variável manipulada é a vazão de eteno (monômero). Estes comportamentos podem ser observados a seguir, nas Figuras 9 e 10.

Estados estacionários instáveis e ciclos limites podem ser explicados matematicamente pela presença de pontos de bifur- cação Hopf, onde pares de conjugado complexo de autovalores da matriz jacobiana do sistema cruzam o eixo imaginário. Fisicamente, o comportamento oscilatório pode ser explicado pelo ganho positivo entre a temperatura do reator e a taxa de produção. Se a temperatura estiver acima do valor de seu estado estacionário instável, então a taxa de calor removido no trocador de calor é maior que a taxa de calor gerado (McAuley et al., 1995). Como resultado, a temperatura começa a diminuir, reduzindo a taxa de reação e a retirada de produto e, com isso, a taxa de catalisador que deixa o reator. Com o acúmulo de catalisador e monômero, a temperatura, a taxa de reação e a retirada de produto voltam a aumentar, reiniciando o ciclo limite. 


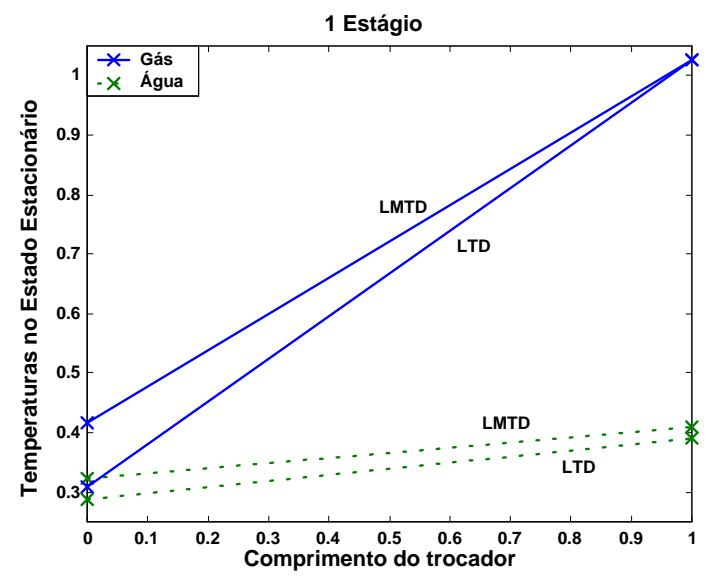

(a)

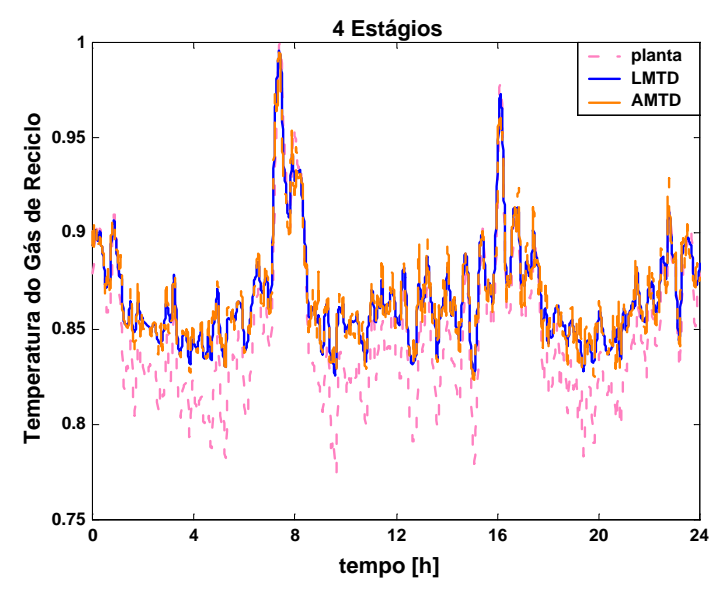

(c)

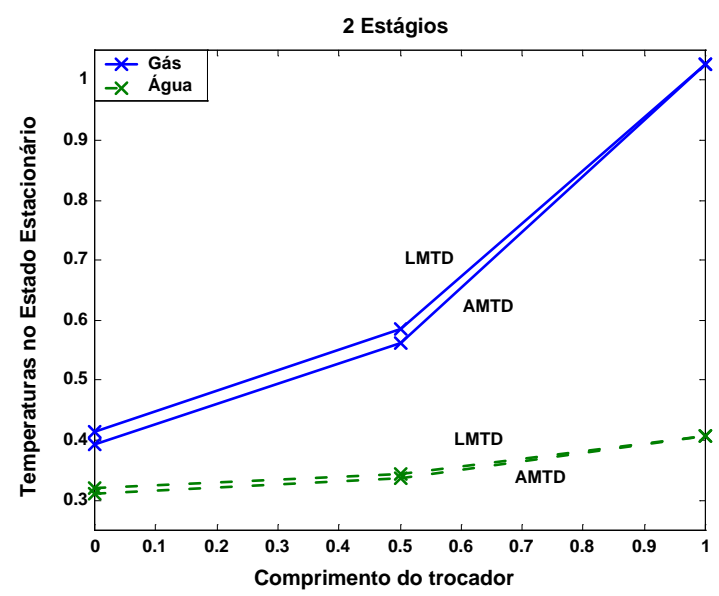

(b)

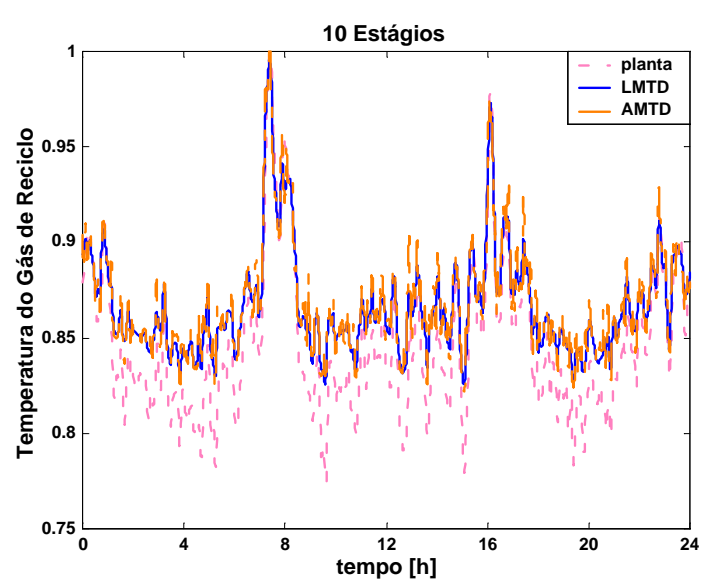

(d)

Figura 7: Comparação entre os perfis de temperatura do gás de reciclo e da água de resfriamento nos modelos com força motriz LTD+AMTD e no modelo com força motriz LMTD para número de estágios variados: um (a), dois (b), quatro (c) e $\operatorname{dez}(\mathrm{d})$.

Os parâmetros livres usados nesta análise são os parâmetros operacionais ou graus de liberdade do reator industrial. Esta análise mostrou que a multiplicidade dos estados estacionários e as bifurcações Hopf foram encontradas na variação da maioria desses parâmetros. Alguns desses parâmetros de bifurcação são: as vazões de catalisador, co-catalisador e gás de reciclo, setpoint da pressão total do reator, a razão molar $\mathrm{O}_{2} / \mathrm{C}_{2}$ (usada no controle do índice de fluidez do polímero) e a temperatura da água de resfriamento.

As Figuras 11 a 15 mostram os efeitos da variação dos parâmetros de bifurcação na estabilidade do reator. As regiões de estabilidade e instabilidade do reator e a localização dos pontos de bifurcação Hopf foram obtidas com o software AUTO $2000 \AA$ desenvolvido por Doedel et al. (2002), que resolve problemas de bifurcação e continuação em EDOs. Os ciclos limites foram obtidos através de simulações do modelo no software MATLAB $\AA$.

Observou-se que, nas condições operacionais reais da planta industrial, os parâmetros de bifurcação, representados pelos valores unitários nos gráficos, encontram-se numa região de instabilidade dos estados estacionários. Entretanto, a observação desses fenômenos no reator industrial real não é possí- 


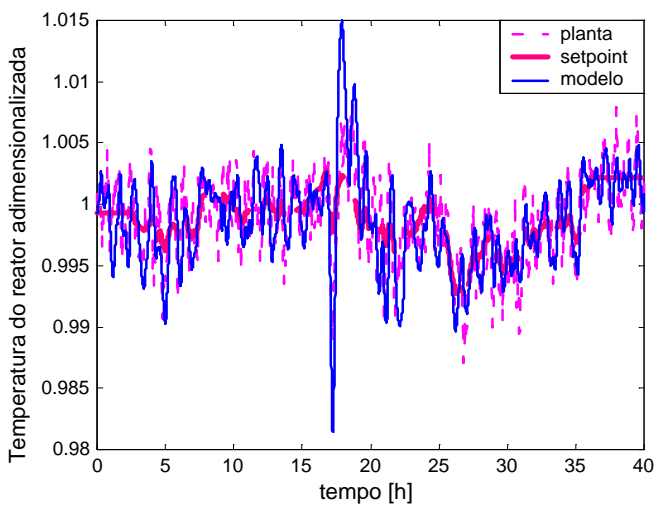

(a)

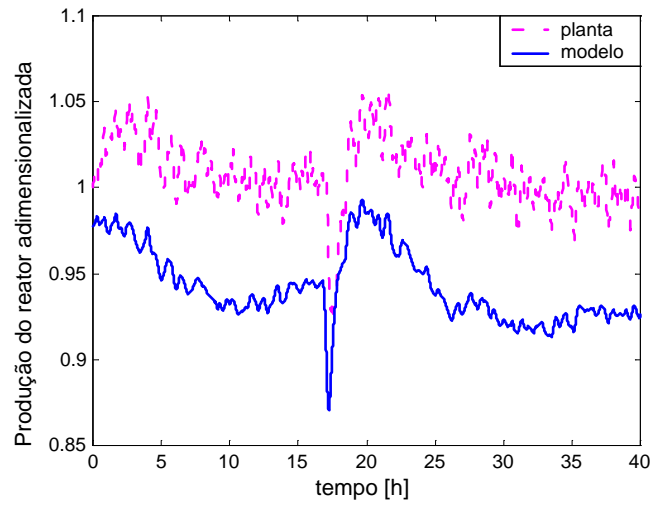

(b)

Figura 8: (a) Temperatura e (b) produção do reator adimensionalizadas: comparação entre a resposta do modelo e os dados da planta industrial.

vel, pois este precisaria operar com a temperatura do seu leito em malha aberta, o que acarretaria em uma baixa produtividade do catalisador e em significativas mudanças nas propriedades do polímero produzido, as quais dependem de que não haja grandes variações de temperatura na zona de reação. Além disso, o ciclo limite, mesmo que estável, possui picos de valor máximo em um valor muito elevado de temperatura e não seria possível operar o reator nessa faixa, uma vez que durante o aumento na temperatura para atingir este pico, ocorreria a fusão do polímero que está sendo produzido e a posterior aglomeração de suas partículas nas paredes desse reator, implicando em paradas e perda de produção. Porém, mesmo que os ciclos não possam ser observados durante a operação do reator industrial real, esses comportamentos podem ser comprovados devido às perdas no controle de tempe-

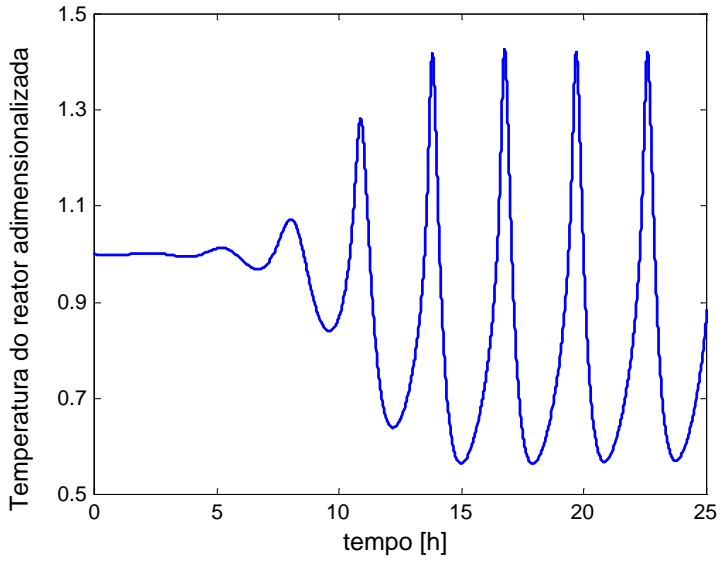

Figura 9: Ciclo limite obtido com a temperatura do reator em malha aberta.

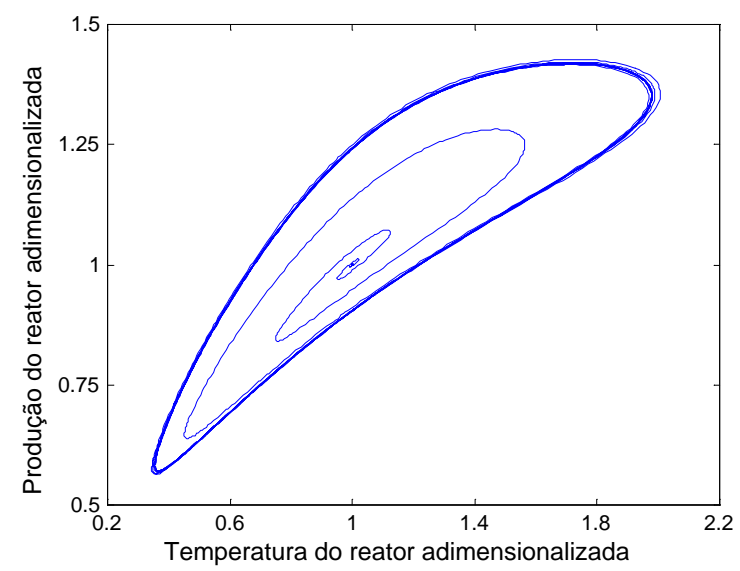

Figura 10: Ciclo limite estável formado pela temperatura e pela produção do reator.

ratura originadas mesmo durante uma situação de operação estável, em que nenhum aumento na carga tenha ocorrido.

\section{CONTROLE DE TEMPERATURA}

O sistema do reator pode ser facilmente estabilizado fechando a malha de temperatura com um controlador proporcional. Entretanto, a adição das ações integral e derivativa elimina o offset e conduz a um desempenho mais rápido do controlador (Dadebo et al., 1997).

Devido à alta não-linearidade existente entre a temperatura do reator e a abertura da válvula, conforme pode ser visto na Figura 16, a relação entre estas variáveis foi caracterizada por um sistema multi-modelos (vários modelos lineares representativos de diferentes regiões de operação). Os modelos 


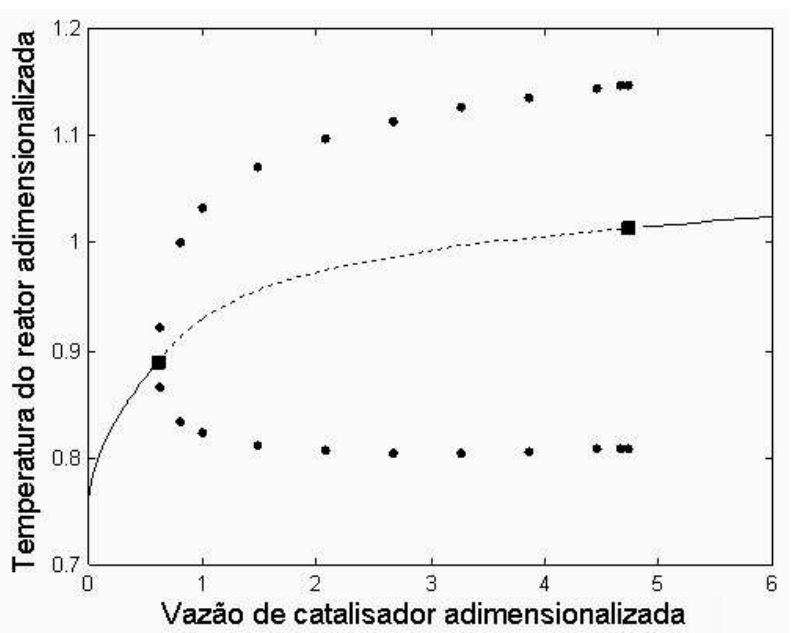

Figura 11: Efeito da vazão de catalisador na estabilidade. estado estacionário estável; — estado estacionário instável; ponto de bifurcação Hopf; • ciclo limite estável.

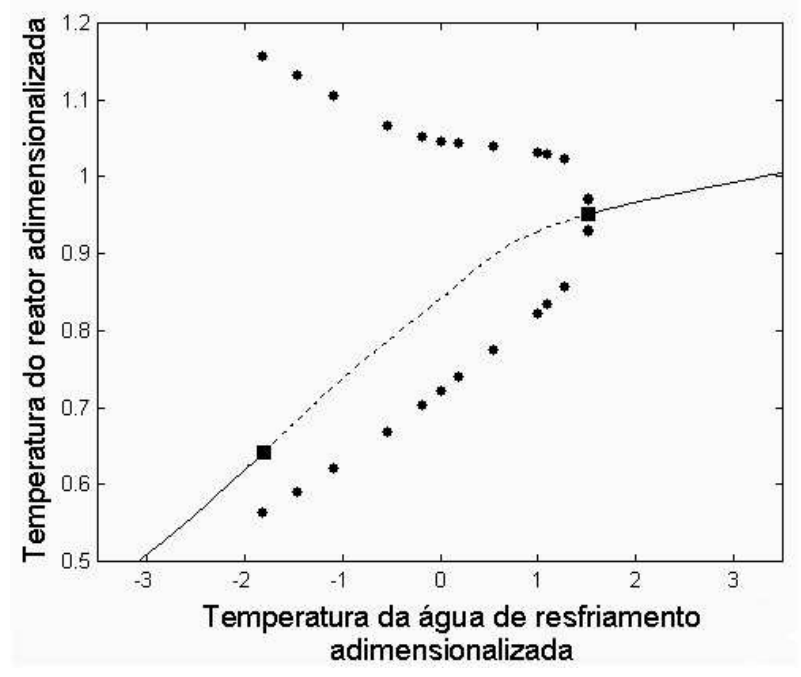

Figura 12: Efeito da temperatura da água de resfriamento na estabilidade. - estado estacionário estável; — estado estacionário instável; $\mathbf{a}$ ponto de bifurcação Hopf; • ciclo limite estável.

lineares foram determinados para os pontos de operação que pertencem à região de instabilidade da abertura da válvula, conforme pode ser visto nesta mesma figura.

Para este sistema de multi-modelos, foram utilizados os métodos SIOM (Sequential Iterative Optimization Method) e MMA (Multi-Model Approach) desenvolvidos por Faccin e Trierweiler (2004 a,b). Este método está baseado em um problema de otimização no domínio da freqüência, e é capaz de projetar os parâmetros de um controlador com desempenho

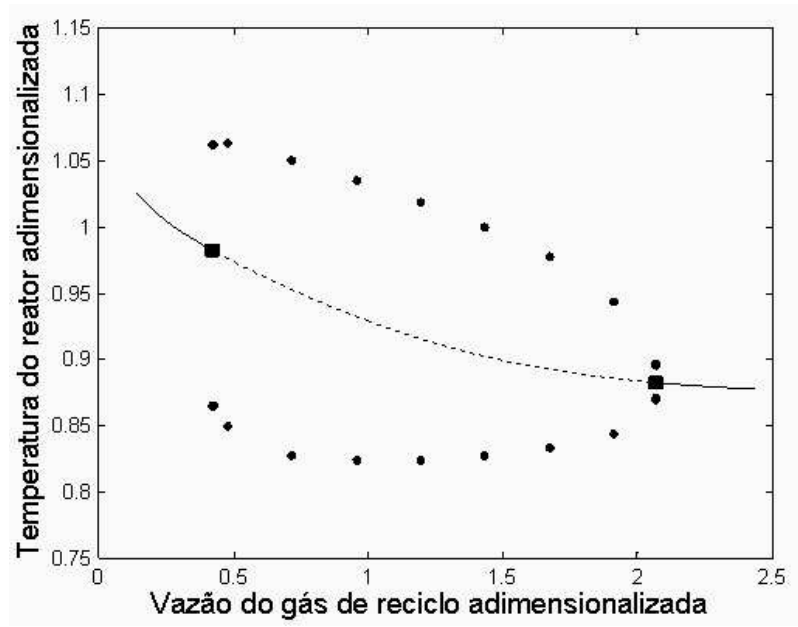

Figura 13: Efeito da vazão do gás de reciclo na estabilidade. — estado estacionário estável; — estado estacionário instável; ponto de bifurcação Hopf; • ciclo limite estável.

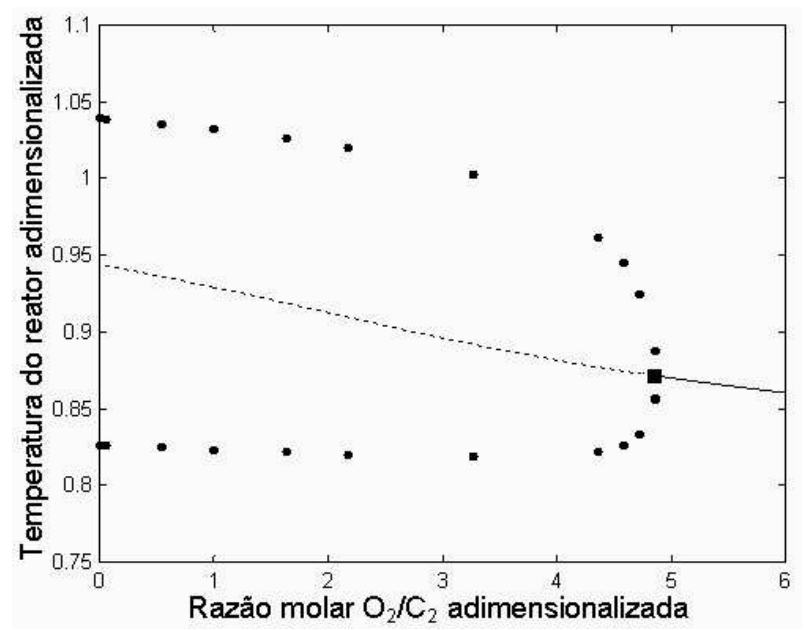

Figura 14: Efeito da razão molar $\mathrm{O}_{2} / \mathbf{C}_{2}$ na estabilidade. estado estacionário estável; — estado estacionário instável; ponto de bifurcação Hopf; • ciclo limite estável.

robusto para operar em diferentes pontos de operação, sendo flexível para a utilização de modelos de ordens e estruturas diferentes. Maiores detalhes sobre a aplicação destes métodos e da análise da estrutura de controle de temperatura, para o caso do reator de polimerização estudado neste artigo, podem ser encontrados em Faccin et al. (2004). Com este método é possível projetar um único controlador para controlar o sistema em todos os pontos de operação com desempenho robusto, pois todos os modelos são considerados no processo de otimização, podendo-se inclusive alterar os pesos de cada modelo, dando maior importância para o modelo limitante (pior caso). O desempenho do controlador robusto pode ser 


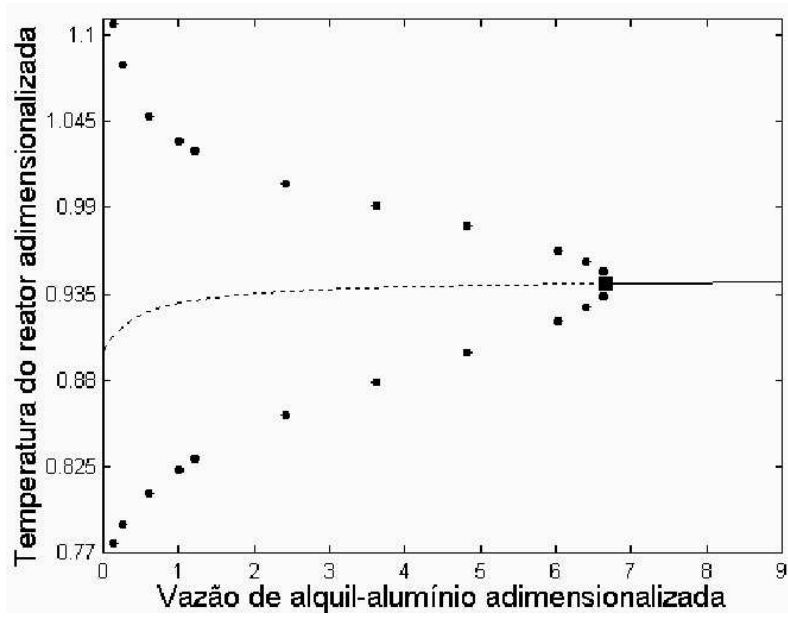

Figura 15: Efeito da fração molar de alquil-alumínio na estabilidade. - estado estacionário estável; — estado estacionário instável; $\square$ ponto de bifurcação Hopf; • ciclo limite estável.

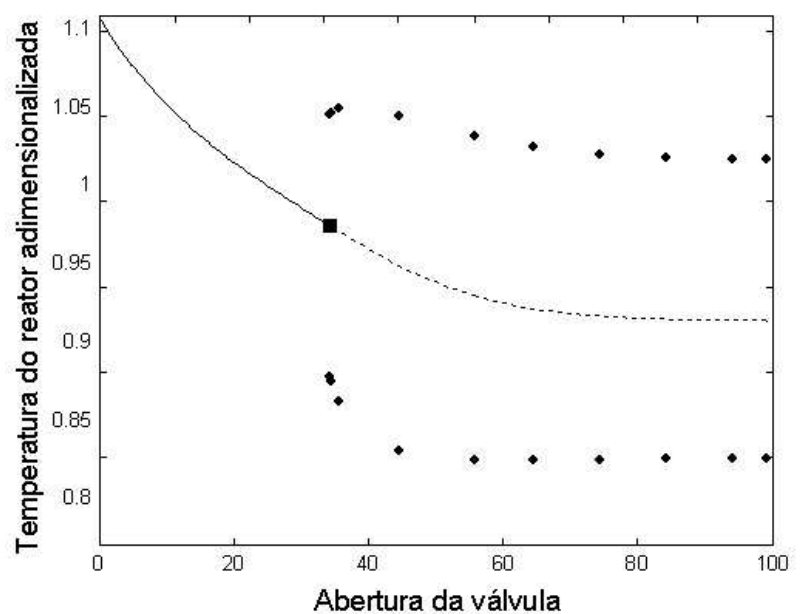

Figura 16: Efeito da abertura da válvula de água de resfriamento na estabilidade. - estado estacionário estável; estado estacionário instável; $\boldsymbol{\square}$ ponto de bifurcação Hopf; • ciclo limite estável.

observado na Figura 17, onde foram consideradas 4 regiões de abertura de válvula pertencentes à região de instabilidade, conforme visto na Figura 16.

Os parâmetros de sintonia do controlador implementado na forma padrão ISA (Instrument Society of America), obtidos com estes métodos, foram $\mathrm{K}_{p}=0,99$ (ação direta), $\tau_{I}=2,07$ min e $\tau_{D}=132,9$ min, que são, respectivamente, o ganho e as constantes de tempo integral e derivativa. A estrutura de controle implementada para estabilizar o reator e a resposta da temperatura a perturbações degrau na abertura da válvula

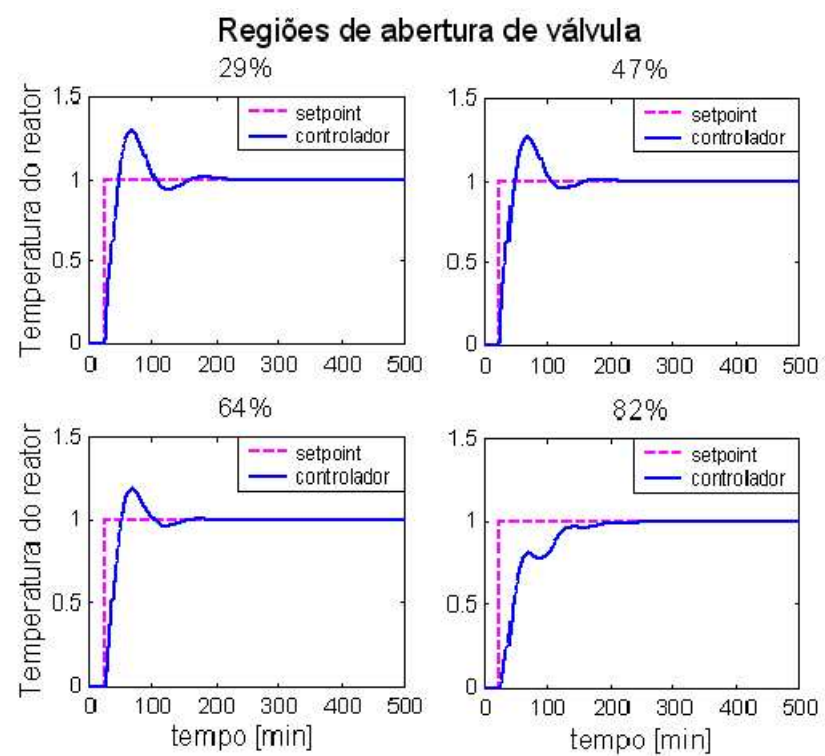

Figura 17: Resposta do PID de temperatura do reator a perturbações degrau no setpoint de temperatura.

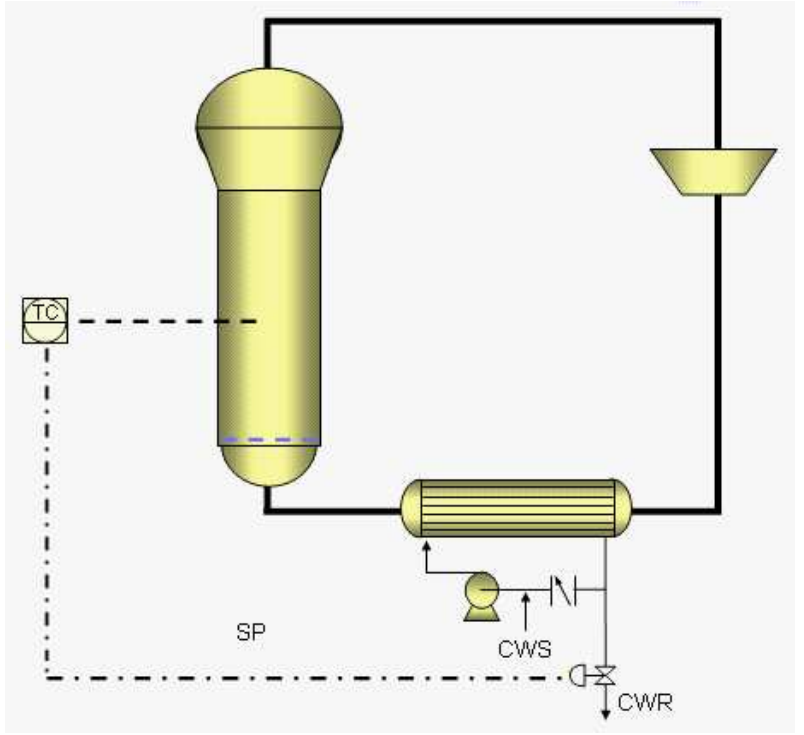

Figura 18: Esquema do controlador PID para temperatura do reator.

de água para resfriamento podem ser vistas nas Figuras 18 e 19 , respectivamente.

Para demonstrar o desempenho do controlador projetado foram feitos testes de controle regulatório (distúrbio na carga), vistos na Figura 19, e testes de controle servo (mudança de setpoint), vistos na Figura 20.

As estratégias do controlador PID de temperatura do reator 

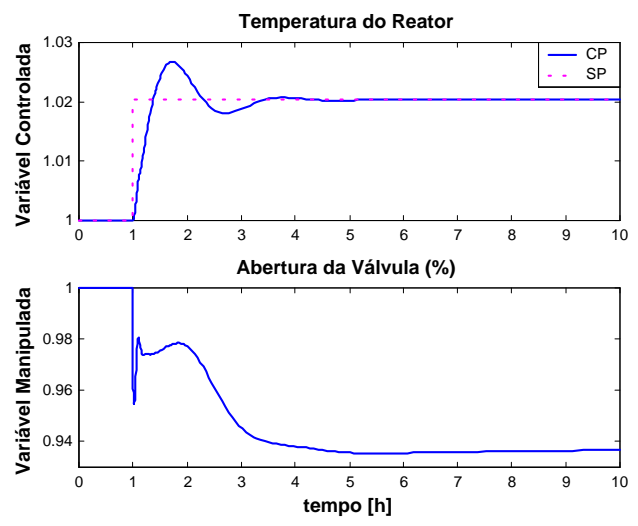

(a)
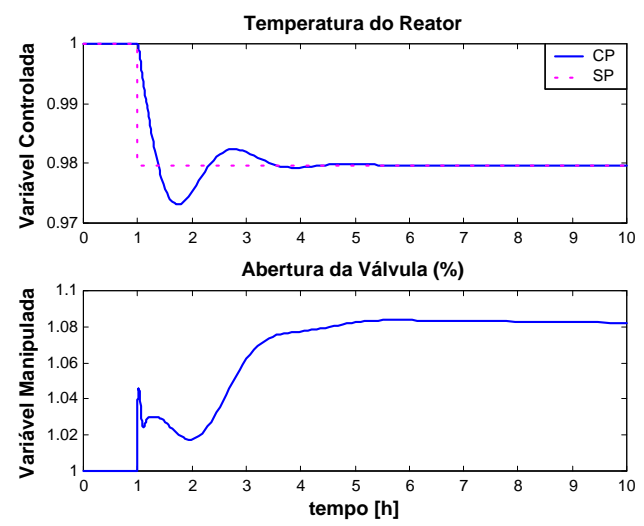

(b)

Figura 19: Resposta do PID de temperatura do reator para uma mudança no setpoint da temperatura do reator de $+2 \%$ (a) e de $-2 \%$ (b) do seu valor original, realizada em tempo $=$ $1 \mathrm{~h}$, utilizando o modelo não-linear.

projetado apresentaram bons resultados na simulação do modelo não-linear do sistema, mostrando que este controlador foi capaz de manter a estabilidade do reator, tanto para o controle servo (Figura 19), quanto para o controle regulatório (Figura 20). Concluiu-se que este controlador tem um bom desempenho, considerando que o tempo médio de residência do polímero no reator industrial estudado é de 2,9 horas, e que proporciona variações menores na temperatura do leito do reator, melhorando a qualidade do polímero gerado. Para manter o valor da temperatura do reator no setpoint desejado, não há necessidade de fazer bruscas variações na abertura da válvula de água para resfriamento.

Na planta industrial é comum encontrar a válvula de con-
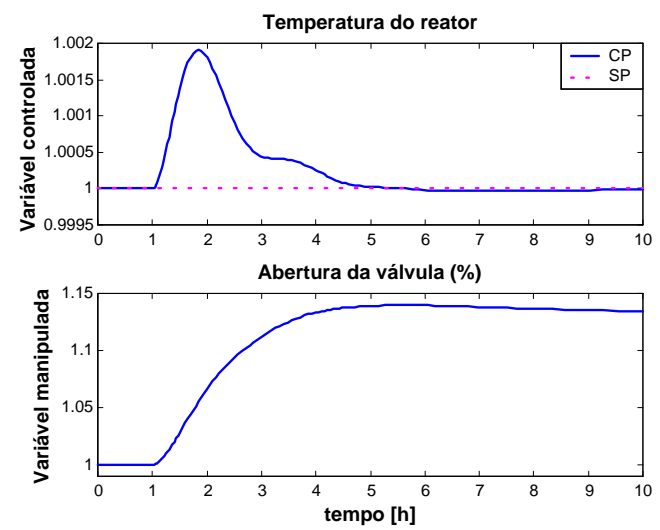

(a)
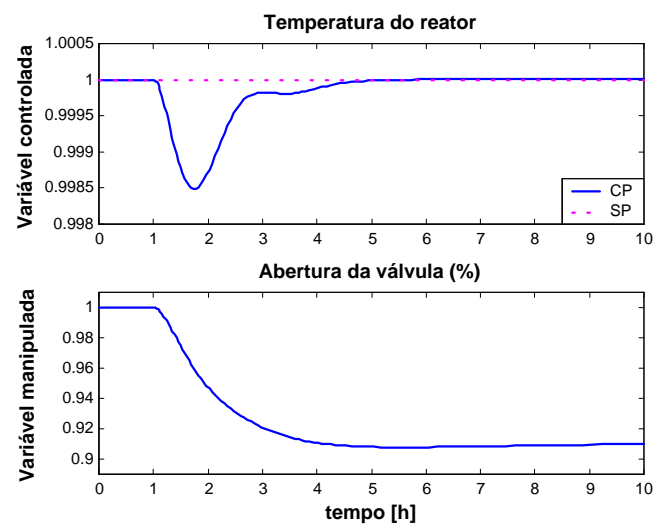

(b)

Figura 20: Resposta do PID de temperatura do reator a variações na vazão de catalisador de $+10 \%$ (a) e de $-10 \%$ (b) do seu valor original, realizada em tempo $=1 \mathrm{~h}$, utilizando o modelo não-linear.

trole próxima às condições de saturação. Se a válvula de controle satura, o reator passa a operar como se o controle de temperatura estivesse em malha aberta, o que conduz o sistema a comportamentos oscilatórios e a ciclos limite, como mostrado na Figura 21. Portanto, somente a manipulação da abertura da válvula não é suficiente para trazer de volta a temperatura do reator para o nível desejado.

Como o controlador demonstrou certa perda de desempenho nas regiões com abertura de válvula próxima à abertura total, o que já era esperado devido aos resultados mostrados na Figura 17, investir em um controlador PID com gain schedule não traria maiores benefícios devido ao pequeno ganho existente entre a abertura da válvula e a vazão de água para a torre 

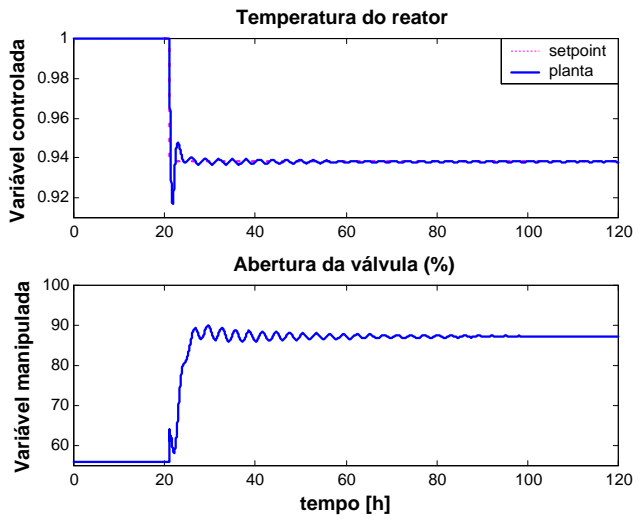

(a)
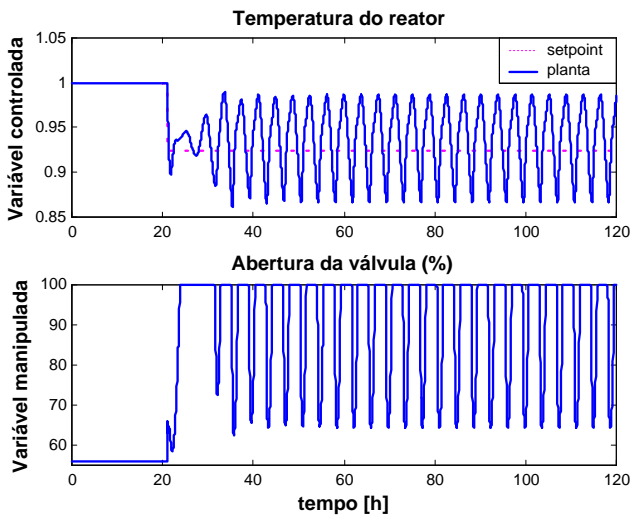

(b)

Figura 21: Resposta do PID de temperatura do reator para uma mudança no setpoint da temperatura do reator de $-6,2 \%$ (a) e de $-7,6 \%$ (b) do seu valor original, realizada em tempo= $20 \mathrm{~h}$, utilizando o modelo não-linear.

de resfriamento, conforme pode ser observado na Figura 4.

O ciclo limite pode ser removido do sistema quando variáveis auxiliares são usadas no controle de temperatura do reator. Essas variáveis podem ser usadas nas estratégias do controlador multivariável da temperatura do reator, onde o aumento da temperatura da água da torre que conduziria o sistema a uma situação de ciclo limite é compensado, evitando a saturação da válvula. Estas alternativas são: a redução da vazão de catalisador para reduzir a produção, o aumento da vazão do inerte saturado de calor específico e massa molar altos que aumenta a troca térmica do gás de reciclo e a redução do setpoint da pressão parcial de eteno (monômero) para evitar que uma quantidade maior desse gás seja injetada ao reator.
Entretanto, todas estas variáveis auxiliares reduzem a taxa de produção e outros problemas podem surgir com seu uso, alguns deles são mostrados na Tabela 5 .

Tabela 5: Problemas no uso de variáveis auxiliares para ajudar no controle da temperatura do reator

\begin{tabular}{|l|l|}
\hline $\begin{array}{l}\text { Variáveis } \\
\text { Auxiliares }\end{array}$ & Problemas \\
\hline $\begin{array}{l}\text { Vazão de ca- } \\
\text { talisador }\end{array}$ & $\begin{array}{l}\text { Dificuldade em determinar a vazão na } \\
\text { alimentadora devido a sua pequena } \\
\text { sensibilidade. Alto impacto na pro- } \\
\text { dução do reator. }\end{array}$ \\
\hline $\begin{array}{l}\text { Vazão de } \\
\text { inerte orgâ- } \\
\text { nico saturado }\end{array}$ & $\begin{array}{l}\text { Este inerte deve ser removido do re- } \\
\text { ator através do fluxo da purga ou do } \\
\text { fluxo da retirada do produto, para pre- } \\
\text { venir o seu acúmulo. A limitação da } \\
\text { quantidade injetada é o ponto de or- } \\
\text { valho dos reagentes. }\end{array}$ \\
\hline $\begin{array}{l}\text { Setpoint } \\
\text { da pressão } \\
\text { parcial de } \\
\text { eteno }\end{array}$ & $\begin{array}{l}\text { Causa uma redução na capacidade de } \\
\text { troca térmica do gás de reciclo, pelo } \\
\text { aumento da razão da concentração ni- } \\
\text { trogênio/eteno. }\end{array}$ \\
\hline
\end{tabular}

A fim de demonstrar a limitação da capacidade térmica do sistema, foi feito um teste onde a temperatura da água da torre, que é o principal distúrbio do sistema em distúrbio, sofreu um aumento suficiente para saturar a válvula e conduzir o sistema a uma condição de formação de ciclos limites, Figura 22.

Na Figura 23 é mostrada uma das alternativas para ser usada nas estratégias do controlador multivariável da temperatura do reator, onde o aumento da temperatura da água da torre que conduziria o sistema a uma situação de ciclo limite, conforme visto na Figura 22, é compensado, evitando a saturação da válvula. Esta alternativa é o aumento da vazão do inerte saturado de calor específico e massa molar altos.

Pela análise da Figura 23, fica evidente o potencial de um controlador multivariável para o controle de temperatura envolvendo, além da abertura da válvula de água para resfriamento, a vazão do inerte orgânico saturado. Testes similares feitos para a vazão de catalisador e para o setpoint da pressão parcial de eteno também apresentaram bons resultados.

\section{CONCLUSÃO}

Os resultados obtidos na análise dos comportamentos dinâmicos demonstram que ao operar com a temperatura do leito em malha aberta, o reator industrial de polimerização em fase gasosa em estudo está propenso a estados estacionários instáveis, a ciclos limite e a estados estacionários inaceitáveis de altas temperaturas. Porém, o uso de estratégias de controle 

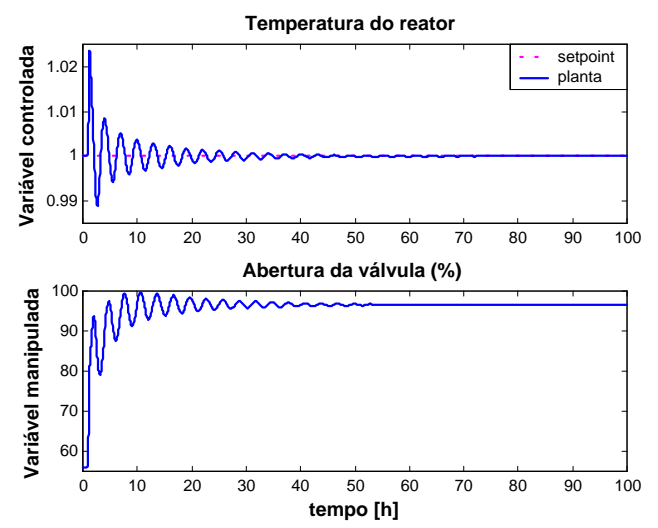

(a)
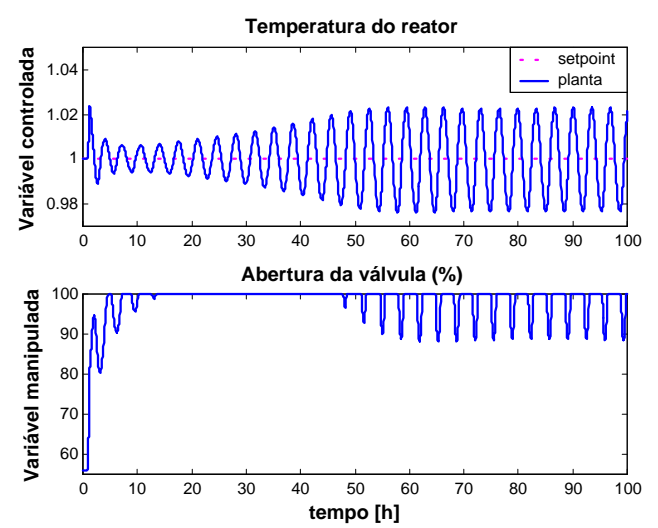

(b)

Figura 22: Resposta do PID de temperatura do reator da temperatura do reator frente a uma mudança na temperatura da água da torre de resfriamento de $+26,2 \%$ (a) e de $+26,6 \%$ (b) do seu valor original, respectivamente, realizada em tempo $=$ $1 \mathrm{~h}$, utilizando o modelo não-linear.

apropriadas para fechar a malha da temperatura do leito evita a instabilidade do reator em consequiência de seus comportamentos dinâmicos.

No projeto do controlador de temperatura, concluiu-se que através de estratégias adequadas de controle, um controlador do tipo PID, projetado via otimização no domínio da frequiência com abordagem multi-modelos, devido à não-linearidade existente entre a temperatura do reator e a abertura da válvula de água para resfriamento, que é a variável manipulada deste controlador, é suficiente para garantir um controle mais estável desta temperatura, melhorando a qualidade do polímero gerado. Para manter o valor da temperatura do reator no set-
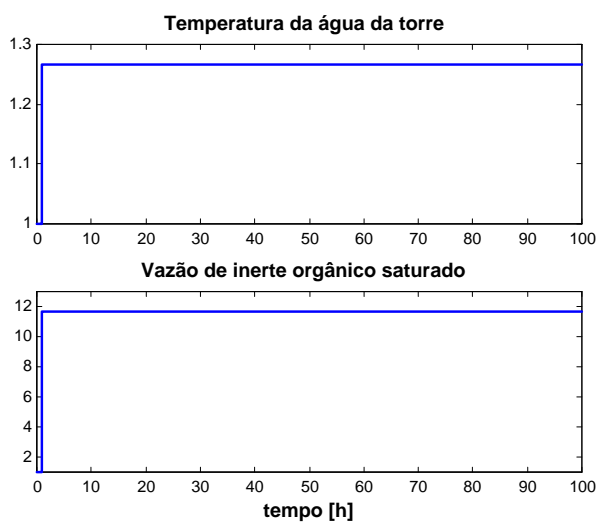

(a)
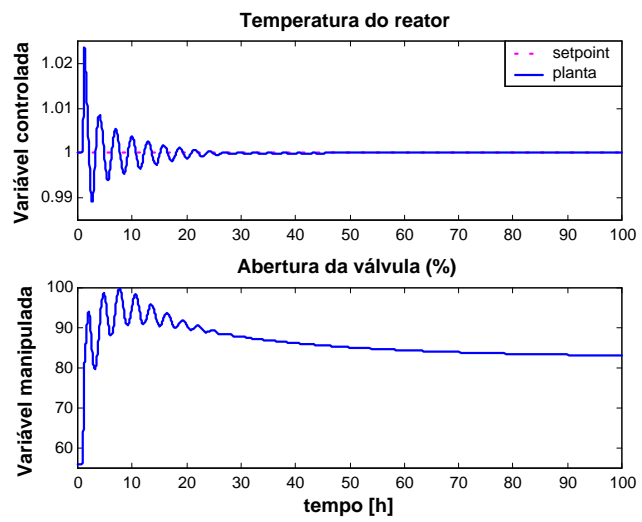

(b)

Figura 23: Resposta do PID de temperatura do reator da temperatura do reator (b) frente a uma mudança na temperatura da água da torre de resfriamento de $+26,6 \%$ do seu valor original e a uma mudança na vazão do inerte orgânico saturado de $+10 x$ (a) do seu valor original, realizada em tempo $=1 \mathrm{~h}$, utilizando o modelo não-linear.

point desejado, não há necessidade de fazer bruscas variações na abertura da válvula de água para resfriamento, como ocorre atualmente na planta industrial em estudo.

Entretanto, concluiu-se que o controle de temperatura não depende apenas da retirada do calor de polimerização do leito através do resfriamento do gás do reciclo. É preciso que a geração deste calor também seja controlada. Isto ocorre porque a torre de resfriamento possui limitação térmica e porque existe uma forte interação entre a temperatura do reator e variáveis tais como a pressão total do reator, a pressão parcial de eteno (monômero) e a produção, que não permitem que 
o controle de temperatura do reator via manipulação da retirada de calor do gás de reciclo, por melhor que o controlador esteja projetado, seja suficiente para manter a temperatura no valor desejado. Este fato também pode ser comprovado na análise dos comportamentos dinâmicos não-lineares e na análise dos dados da planta industrial, onde se observou a forte influência das variáveis citadas, principalmente quando há limitação térmica do sistema. Estas variáveis proporcionam o aumento das regiões operacionais de estados estacionários instáveis, conduzindo o reator a comportamentos dinâmicos não-lineares, tais como pontos de bifurcação Hopf e ciclos limite estáveis

A fim de prever a influência destas variáveis, seria interessante o desenvolvimento de um controlador multivariável para este sistema com o uso de algumas variáveis, tais como a vazão de catalisador, a vazão de inerte orgânico saturado e o setpoint da pressão parcial de eteno, nas estratégias de controle. Neste caso, quando a abertura da válvula de água para resfriamento tender à saturação e não for mais possível a retirada de calor do gás de reciclo para reduzir a temperatura do reator, pode-se fazer o uso destas variáveis.para trazer a temperatura do reator de volta pra o nível desejado.

\section{REFERÊNCIAS}

Alsop, A.W. e Edgar, T.F. (1989). Nonlinear heat exchanger control through the use of partially linearized control variables. Chemical Engineering Communications, Vol. 75, pp. 155-170.

Choi, K.Y. e Ray, W.H. (1985). The dynamic behavior of fluidized bed reactors for solid catalyzed gas phase olefin polymerization, Chemical Engineering Science, Vol. 40, No. 12, pp. 155-17040.

Dadedo, S. A., Bell, M. L., McLellan, P. J. e McAuley, K. B. (1997). Temperature control of industrial gas phase polyethylene reactors, Journal of Process Control, Vol. 7, No. 2, pp. 83-95.

Doedel, E. J., Paffenroth, R. C., Champneys, A. R., Fairgrieve, T. F., Kuznetsov, Y. A., Oldeman, B. E., Sandstede, B. and Wang, X. (2002). Applied mathematics report, California Institute of Technology, Pasadena.

Faccin, F. e Trierweiler, J. O. (2004a). A novel tool for multimodel PID controller design. $7^{\text {th }}$ DYCOPS Symposium. Cambridge.

Faccin, F. and Trierweiler, J. O. (2004b). Performance Limitations of Some Industrial PID Controllers. $14^{\text {th }} E S$ CAPE Symposium. Lisboa.

Faccin, F., Salau, N. P. G., Secchi, A. R., Trierweiler, J. O., Neumann, G. A. e Toledo, A. M. (2004). Análise da es- trutura de controle de temperatura de um reator de polimerização de polietileno em leito fluidizado. $15^{\circ} \mathrm{CBA}$, Brasil, 2004.

Gambetta, R. (2001). Modelagem e simulação de reatores em leito fluidizado. Dissertação de Mestrado - PPGEQ. Universidade Federal do Rio Grande do Sul, Brasil.

Ghasem, N. M. (1999). Effect of polymer particle size and inlet gas temperature on the industrial gas phase fluidized bed reactor. Chemical Engineering Tecnology, Vol. 22, No. 9 , pp. 777-783.

Ghasem, N. M. (2000). Dynamic behaviour of industrial gas phase fluidized bed polyethylene reactors under PI control. Chemical Engineering Tecnology, Vol. 23, No. 2 , pp. 133-140.

Kunii, D. e Levenspiel, O. (1991). Fluidization engineering. New York: Butterworth-Heinemman.

Lagemann, B. (1989). Modelling, Simulation and Control of Fluidized Bed Reactor for the Gas Phase Polimerization of Olefins. Master of Science Thesis. University of Wisconsin, Madison.

McAuley, K.B. (1991). Modelling, estimation and control of product properties in a gas phase polyethylene reactor. Ph.D. Thesis. McMaster University, Ontario.

McAuley, K.B., Talbot, J.P. e Harris, T.J. (1994). A comparison of two-phase and well-mixed models for fluidizedbed polyethylene reactors. Chemical Engineering Science, Vol. 49, No. 13, pp. 2035-2045.

McAuley, K. B., MacDonald, D. A. and McLellan, P. J. (1995). Effects of operating conditions on stability of gas-phase polyethylene reactors. AIChe Journal, Vol. 41, No. 4, pp. 868-879.

Pinto, J. C. (1991). Uma revisão sobre sistemas dinâmicos não-lineares, teoria de bifurcações e comportamento dinâmico de sistemas da engenharia química. $R B E$, Vol. 8, No. 2, pp. 5-65.

Ray, W. H. and Villa, C. M. (2000). Nonlinear dynamics found in polymerization - a review, Chemical Engineering Science, Vol. 55, pp. 275-290.

Xie, T., McAuley, K. B., Hsu, J.C.C. e Bacon, D.W. (1994). Gas phase ethylene polymerization: Production process, polymer properties, and reactor modeling, Industrial and Engineering Chemistry Research, Vol. 33, pp. 449-479.

Zacca, J.J. (1995). Distributed parameter modeling of the polymerization of olefins in chemical reactors. Ph.D. Thesis. University of Wisconsin, Madison. 